\title{
Temperature Calibration of a Specimen-heating Holder for Transmission Electron Microscopy
}

\author{
Tae-Hoon Kim, Jee-Hwan Bae, Jae-Wook Lee, Keesam Shin ${ }^{1}$, Joon-Hwan Lee ${ }^{2}$, \\ Mi-Yang Kim², Cheol-Woong Yang* \\ School of Advanced Materials Science \& Engineering, Sungkyunkwan University, Suwon 440-746, Korea \\ ${ }^{1}$ School of Nano and Advanced Materials Engineering, Changwon National University, Changwon 641-773, Korea \\ ${ }^{2}$ Advanced Materials \& Device Lab., Corporate R\&D Institute, Samsung Electro-Mechanics Co., Suwon 443-743, Korea
}

*Correspondence to:

Yang CW,

Tel: +82-31-290-7362

Fax: +82-31-290-7371

E-mail: cwyang@skku.edu

Received June 16, 2015

Revised June 25, 2015

Accepted June 25, 2015
The in-situ heating transmission electron microscopy experiment allows us to observe the time- and temperature-dependent dynamic processes in nanoscale materials by examining the same specimen. The temperature, which is a major experimental parameter, must be measured accurately during in-situ heating experiments. Therefore, calibrating the thermocouple readout of the heating holder prior to the experiment is essential. The calibration can be performed using reference materials whose phase-transformation (melting, oxidation, reduction, etc.) temperatures are well-established. In this study, the calibration experiment was performed with four reference materials, i.e., pure Sn, Al-95 wt $\% \mathrm{Zn}$ eutectic alloy, $\mathrm{NiO} /$ carbon nanotube composite, and pure $\mathrm{Al}$, and the calibration curve and formula were obtained. The thermocouple readout of the holder used in this study provided a reliable temperature value with a relative error of $<4 \%$.

Key Words: Melting point, Dynamic observation, Annealing, Thermocouple, In-situ transmission electron microscopy

\section{INTRODUCTION}

The electron microscope is capable of resolving crystal lattices and the resulting images can be interpreted from the viewpoint of atomic positions (Menter, 1956; Cowley \& Iijima, 1972). As such, the use of high-resolution transmission electron microscopy (HR-TEM) has increased significantly, and HR-TEM has become an essential tool in material characterization. HR-TEM is especially effective in resolving nanoscale features, as is the case of various types of material interfaces (Holloway \& Sinclair, 1987; Sinclair et al., 1989; Sinclair, 1990). However, like other ex-situ analysis techniques, HR-TEM is somewhat inadequate for the analysis of dynamic behavior, because the information is obtained from separate samples that undergo different processing. Therefore, determining the exact sequence of events during heating is sometimes difficult and tedious; important steps in the process may be missed, and the sequence may be completely misinterpreted. These problems are frequently encountered in the study of interfacial chemistry during dynamic reactions.

To facilitate dynamic observations, HR-TEM may be used in conjunction with in-situ heating of the sample inside the microscope. In-situ heating analysis is both unique and highly effective in making these observations and is therefore frequently combined with other types of characterization such as conventional TEM and X-ray diffraction (Glicksman \& Schaefer, 1966; Glicksman \& Vold, 1966; Butler \& Hale, 1981; Raaijmakers et al., 1987; Beam \& Chung, 1985). Insitu heating TEM has also been successfully used for the dynamic observation of atomic-scale events in experiments that employed a high-energy imaging electron beam for heating the sample (Hashimoto et al., 1980; Yamashita \&

This work was supported in part by the NRF grants funded by the Korean government (MSIP and MTIE) (No. 2011-0019984, No. 2011-0030058 and No. 10041134) and partly by grants funded by Samsung Electro-Mechanics Co. through the Interface Research Center at Sungkyunkwan University.

@ This is an open-access article distributed under the terms of the Creative Commons Attribution Non-Commercial License (http://creativecommons.org/licenses/by-nc/4.0) which permits unrestricted noncommercial use, distribution, and reproduction in any medium, provided the original work is properly cited.

Copyrights @ 2015 by Korean Society of Microscopy 
Sinclair, 1983; Bovin \& Smith, 1985; Eyring et al., 1985; Iijima \& Ichihashi, 1986). These results are important for the study of the effect of electron-beam-induced heating, but differ significantly from those obtained with the actual thermal heating that occurs during material processing. Natural thermal heating of the sample is especially important for semiconductor materials that undergo several thermal cycles during device processing.

In order to produce experimental results by natural thermally activated processes, the sample must be heated externally in a holder with an embedded heating system, as successfully demonstrated by a number of research groups (Gibson et al., 1985; Sinclair et al., 1987; Sinclair et al., 1988; Smith et al., 1993). This was achieved despite the fact that heating holders were sometimes not sufficiently stable to allow HR-TEM image recording at elevated temperatures.

The temperature of the specimen, which is typically measured by a thermocouple during the annealing experiment, constitutes an important parameter in in-situ annealing experiments in a TEM. However, the thermocouple in the heated TEM holder is not in direct contact with the specimen, and hence the measured and actual temperatures of the region of interest in the sample, may differ. Measuring the actual temperature of the specimen during in-situ heating and determining the temperature dependence of the dynamic reactions is therefore essential. This can be achieved by performing a calibration experiment with standard specimens prior to the in-situ heating experiment. This article briefly reviews various methods of temperature calibration for a specimenheating holder. The procedure and result of the temperature calibration experiment, performed on pure elements ( $\mathrm{Sn}$ and $\mathrm{Al}$ ) and $\mathrm{NiO} /$ carbon nanotube (CNT) composites, is described.

\section{MATERIALS AND METHODS}

The in-situ annealing experiments were performed at $300 \mathrm{kV}$ in a JEOL-3011 (JEOL Co., Ltd., Japan) equipped with a $\mathrm{LaB}_{6}$ filament. Fig. 1 shows the setup used for the in-situ annealing

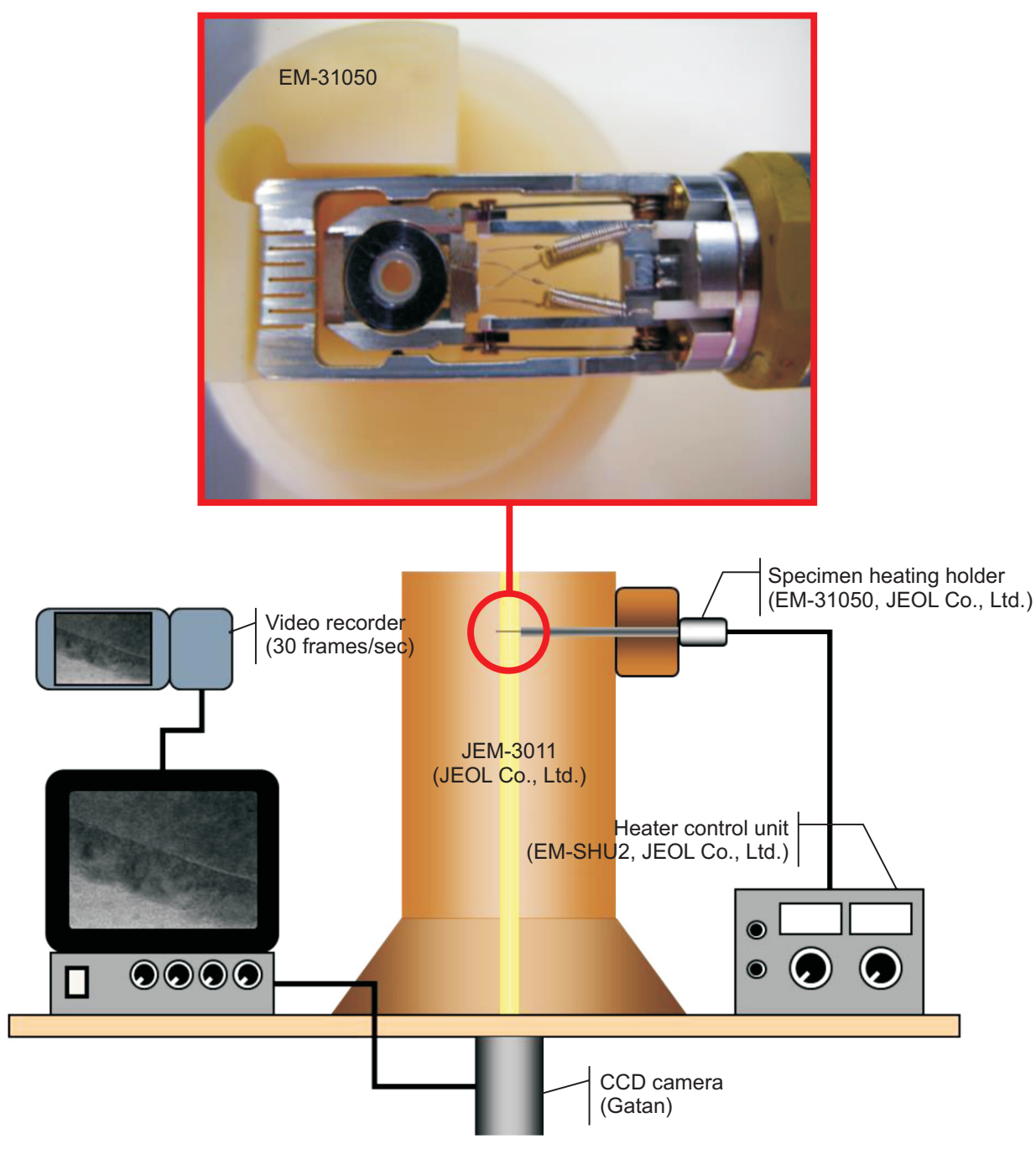

Fig. 1. Schematic of the in-situ annealing and recording system equipped with a JEOL EM-31050 (JEOL Co., Ltd., Japan) specimen-heating double-tilting holder. CCD, charge-coupled device. 
experiments. A model EM-31050 JEOL heating holder (JEOL Co., Ltd.) equipped with a Pt/Pt-13\%Rh thermocouple in contact with the furnace was used to resistively heat the specimens and measure the temperature of the specimen up to $900^{\circ} \mathrm{C}$. In addition to normal photographic recording, images from a Gatan 622 TV rate camera system (Gatan, USA) were recorded on video tape at a time resolution of 30 frames per second (fps). Most of the images were extracted from video tapes recorded at different stages of the experiments; figures taken from the video recording are identified by the descriptions in the captions.

\section{RESULTS AND DISCUSSION}

As previously mentioned, the thermocouple of the specimenheating holder is typically in direct contact with the furnace and not with the specimen; determining the temperature difference between the measured and actual temperature values of the area of interest in the TEM specimen is essential. Several methods for calibrating the temperature of the specimen-heating holder have been reported. These include:

\section{Solid-phase Epitaxial Regrowth}

When annealed, ion-implanted amorphized surface layers of $\mathrm{Si}$ and Ge crystallize via the movement of the sharp crystal/ amorphous interface toward the free surface. The thickness of the epitaxially crystallized layer increases with time at a given temperature resulting eventually in a single-crystal epitaxial film. The corresponding growth rates are well-described by an Arrhenius dependence on temperature, with activation energies of 2.70 and $2.00 \mathrm{eV}$ for $\mathrm{Si}$ and Ge, respectively. The effects of dopants and ion irradiation on the growth process in Si have also been extensively studied (Olson \& Roth, 1988). Stach et al. (1998) investigated the temperature calibration of the TEM heating holder using a combination of solidphase epitaxial regrowth and the focused ion beam sample preparation technique. They carefully examined the regrowth region from a sample annealed for $30 \mathrm{~min}$ at a thermocouple reading of $575^{\circ} \mathrm{C}$. The measured regrowth velocity for this sample was $4.4 \mathrm{~nm} / \mathrm{sec}$, which indicates that the thermocouple reading was highly accurate in this case. Interestingly, the thermocouple readout on the other heating holder used in their laboratory was consistently $25^{\circ} \mathrm{C}$ lower than the actual temperature determined from the regrowth experiments performed on amorphous Si. This emphasizes the importance of carefully calibrating individual holder.

\section{Metal-Mediated Crystallization}

Early studies on amorphous Si showed that the crystallization temperature of $\mathrm{Si}$ is significantly reduced when metal contacts are used. This phenomenon, referred to as metal-catalyzed or metal-mediated crystallization (MMC), has been extensively studied in $\mathrm{Ge} / \mathrm{metal}$ and $\mathrm{Si} /$ metal systems.

Sinclair and Konno (1994) showed that the MMC of Ge in Ag-Ge multilayers occurs at a temperature of $270^{\circ} \mathrm{C} \sim 280^{\circ} \mathrm{C}$, which is $\sim 240^{\circ} \mathrm{C}$ lower than that of pure amorphous Ge. Their observations indicated that $\mathrm{Ge}$ atoms from the amorphous phase diffused through the Ag grains and precipitated onto the crystalline phase. They also described in-situ high-resolution electron microscopy of the MMC of semiconductors, particularly for the Ag-Ge and Ag-Si systems. More importantly, the kinetics, thermodynamics, and insitu observations were mutually consistent. Hence, the in-situ crystallization reaction occurred at the same temperature as that of the exothermic reaction peak observed in the results of calorimetry measurements. This crystallization reaction can therefore be used as a reference to calibrate the thermocouple readout on the heating holder.

\section{Melting Point Measurement}

Standard materials with accurately determined solid?liquid phase transition temperatures (melting points) can be used for the calibration. Melting begins at the edge of the sample and proceeds to the interior. In addition, thickness contours that occur at heating temperatures up to the melting point, allow easy identification of the solid-liquid interface.

Kang (2009) examined the melting behavior of the Sn$3.5 \mathrm{Ag}\left(T_{m}=222^{\circ} \mathrm{C}\right)$ alloy with increasing temperature from room temperature to $190^{\circ} \mathrm{C}$ (the temperature indicated by the heating controller). The alloy began melting at a lower temperature $\left(\sim 170^{\circ} \mathrm{C}\right)$ than the established melting temperature. This suggests that the actual specimen temperature is higher than that indicated by the thermocouple readout. The temperature difference between the TEM specimen and the thermocouple readout was found to be $\sim 50^{\circ} \mathrm{C}$.

\section{Direct Temperature Measurement}

The temperature of the heating holder can be measured by a pyrometer, which is a non-contact device that intercepts and measures thermal radiation in a process referred to as pyrometry. A pyrometer has an optical system and a detector and hence temperature measurements must be performed in a specially designed vacuum chamber. Using this chamber, Lee (2006) obtained a calibration curve for the temperature of graphite flakes by performing a series of heating experiments with a tungsten filament (heating element). During the experiments, the temperature of the filament was measured by monitoring the melting of pure substances such as $\mathrm{Sn}$ and Au. Pyrometers (MINOLTA IR-308, TR-630A; Minolta, Japan) were used to complete the calibration for measurements at temperatures of $300^{\circ} \mathrm{C} \sim 2,000^{\circ} \mathrm{C}$. The results of these measurements revealed that the temperature of the graphite flake (substrate) differed only slightly from that of the filament. 

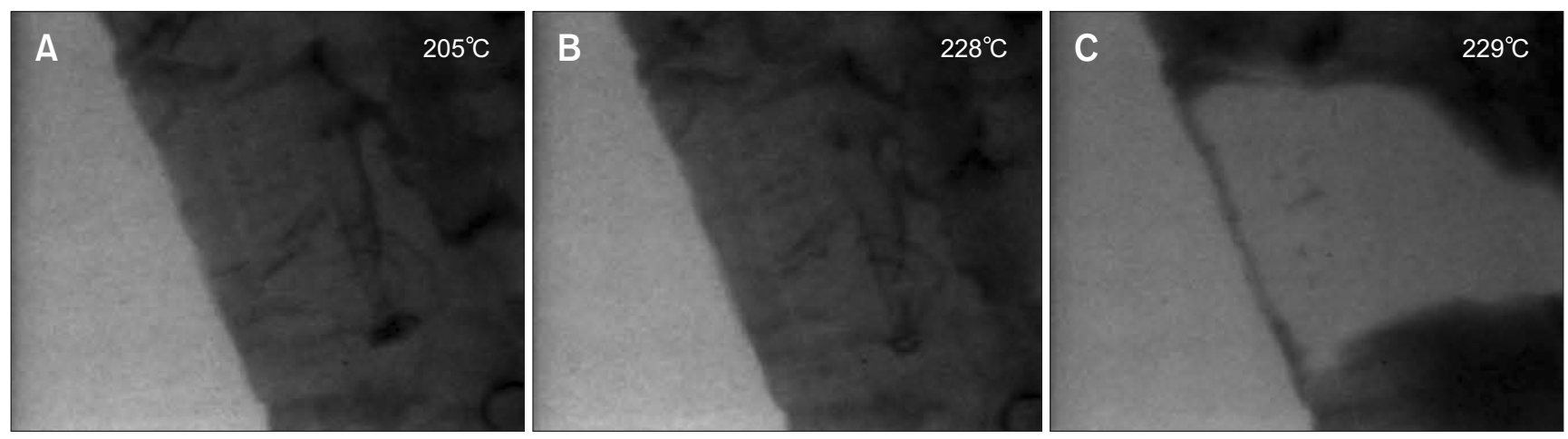

Fig. 2. Individual frames digitized from a video sequence recorded using pure Sn during annealing at temperatures ranging from room temperature to $229^{\circ} \mathrm{C}$.

\section{Temperature Calibration for Our Specimen Heating Holder}

In order to obtain the temperature calibration curve, the calibration experiment was performed with four specimens namely, pure Sn, Al-95 wt\%Zn eutectic alloy, $\mathrm{NiO} / \mathrm{CNT}$ composite, and pure $\mathrm{Al}$ (listed in the order of target temperature to be calibrated).

Pure $\mathrm{Sn}$ with a known melting temperature of $\sim 231^{\circ} \mathrm{C}$, can be used in the low-temperature range of the melting point measurement method. The specimen was heated from room temperature to $230^{\circ} \mathrm{C}$ (the temperature indicated by the heating controller) and was abruptly transformed at $229^{\circ} \mathrm{C}$, from a crystalline solid into an amorphous liquid. Fig. 2 shows that the pure Sn starts to melt at $229^{\circ} \mathrm{C}$, indicated by the thermocouple readout, which is slightly lower than the known melting temperature $\left(231^{\circ} \mathrm{C}\right)$. This result demonstrates that the temperatures of the TEM specimen and the thermocouple readout on the heating controller are almost the same in the low-temperature regime. However, the temperatures deviate appreciably with increasing temperature, as observed in the in-situ heating experiment performed on an $\mathrm{Al}-95 \mathrm{wt} \% \mathrm{Zn}$ eutectic alloy, whose melting point is $382^{\circ} \mathrm{C}$. In that case, the thermocouple readout was $7^{\circ} \mathrm{C}$ lower than the actual temperature of the specimen (the melting temperature of the alloy).

At intermediate temperatures of $\sim 500^{\circ} \mathrm{C}$, a nano-composite in which $\mathrm{NiO}$ nanoparticles are attached to a CNT can be used as an effective calibration standard. Fig. $3 \mathrm{~A}$ shows the results of thermo-gravimetric analysis of two NiO/CNT nano-composites with different $\mathrm{NiO}$ contents. Both samples exhibited weight losses, and peaks occurred in the derivative thermo-gravimetric (DTG) plots at $\sim 530^{\circ} \mathrm{C}$. Moreover, the oxygen in the $\mathrm{NiO}$ constituted the only source for oxidizing the CNTs. Therefore, the CNTs were oxidized at the interface between the $\mathrm{NiO}$ and $\mathrm{CNT}$ by consuming oxygen from $\mathrm{NiO}$, reducing $\mathrm{NiO}$ to $\mathrm{Ni}$ at the peak temperature of the DTG plots. The temperature at which the $\mathrm{NiO} \rightarrow \mathrm{Ni}$ phase transition occurs is measured by using a TEM to observe the dynamic changes in the diffraction patterns of $\mathrm{NiO}$. At $500^{\circ} \mathrm{C}$ on the
A

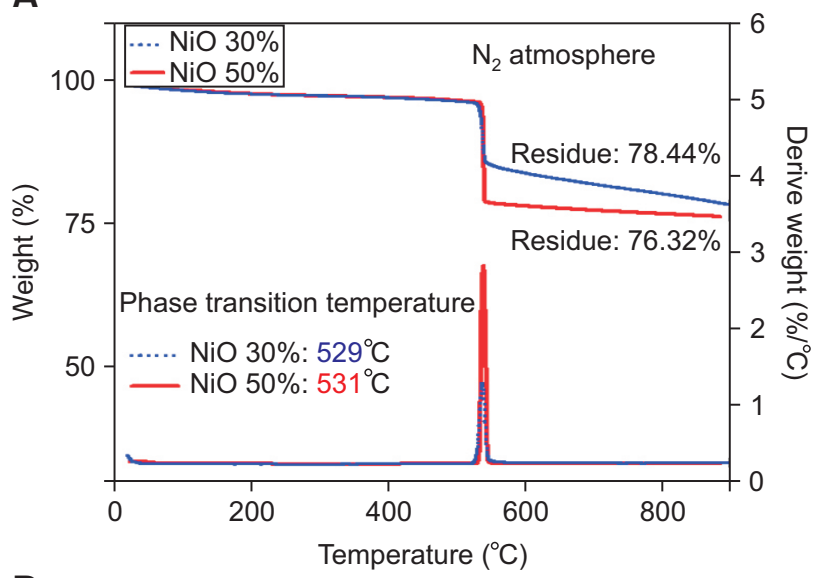

B

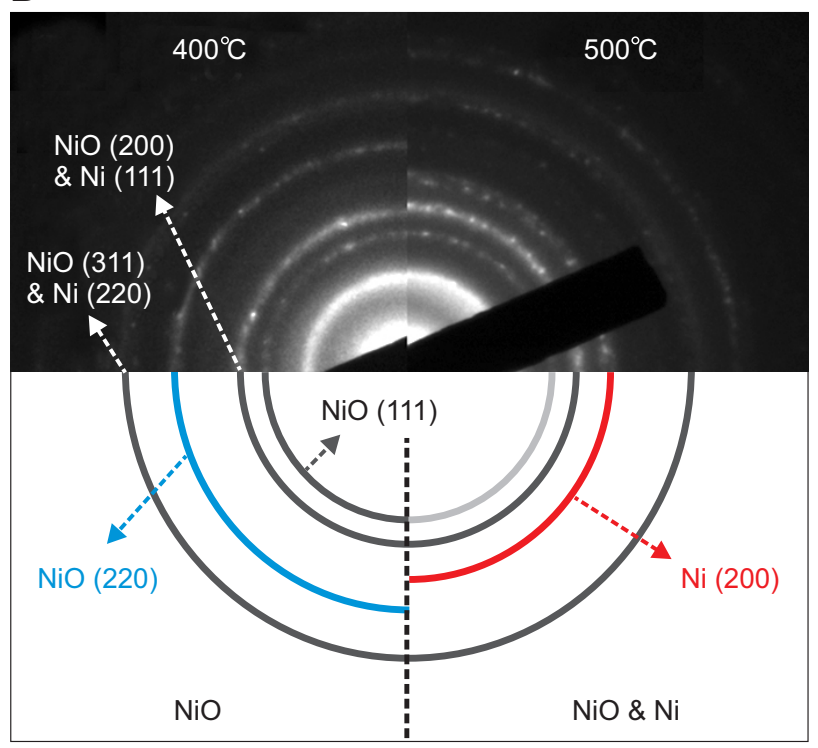

Fig. 3. (A) Results from the thermo-gravimetric analysis analysis of $\mathrm{NiO} /$ carbon nanotube composite under $\mathrm{N}_{2}$ atmosphere demonstrate that the phase transition $\left(\mathrm{NiO} \rightarrow \mathrm{Ni}\right.$ ) occurs at $530^{\circ} \mathrm{C}$. (B) Dynamic change in selected area diffraction patterns during the in-situ heat-treatment performed inside the transmission electron microscopy. The left and right patterns obtained at $400^{\circ} \mathrm{C}$ and $500^{\circ} \mathrm{C}$ consist of diffraction rings corresponding to $\mathrm{NiO}$ and $\mathrm{Ni}$, respectively. 

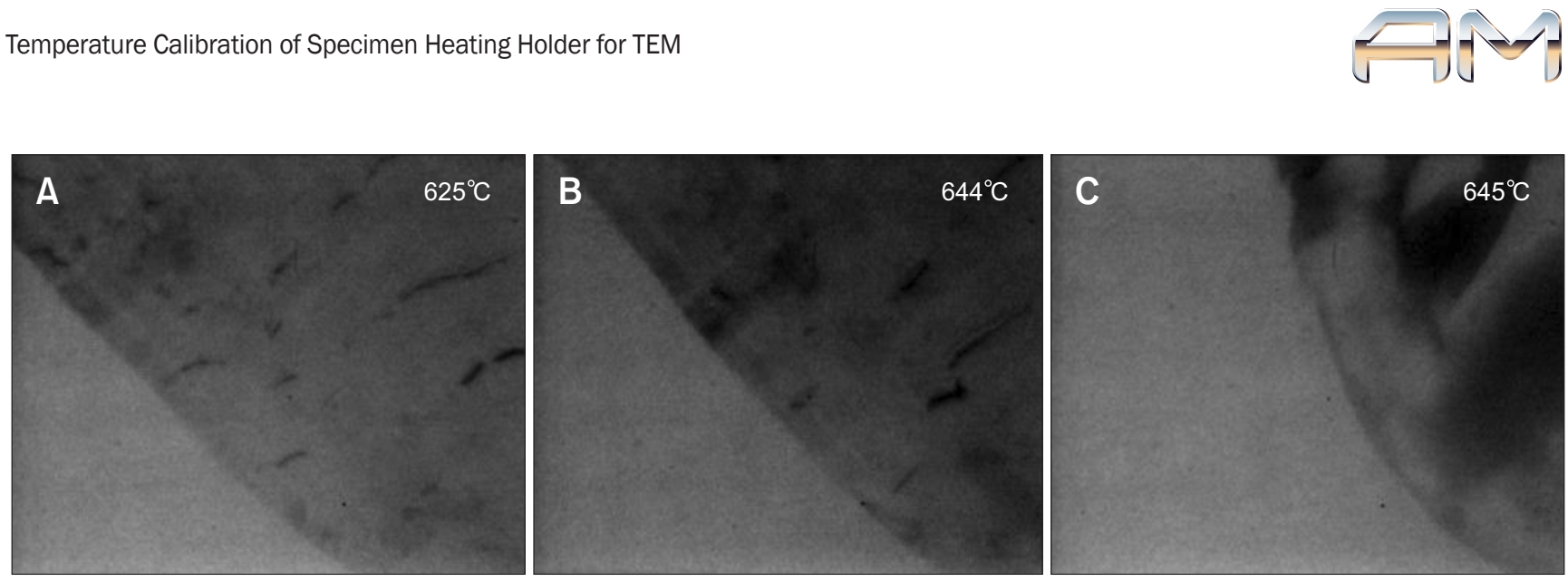

Fig. 4. Individual frames digitized from a video sequence recorded using pure $\mathrm{Al}$ during annealing at temperatures ranging from room temperature to $645^{\circ} \mathrm{C}$.

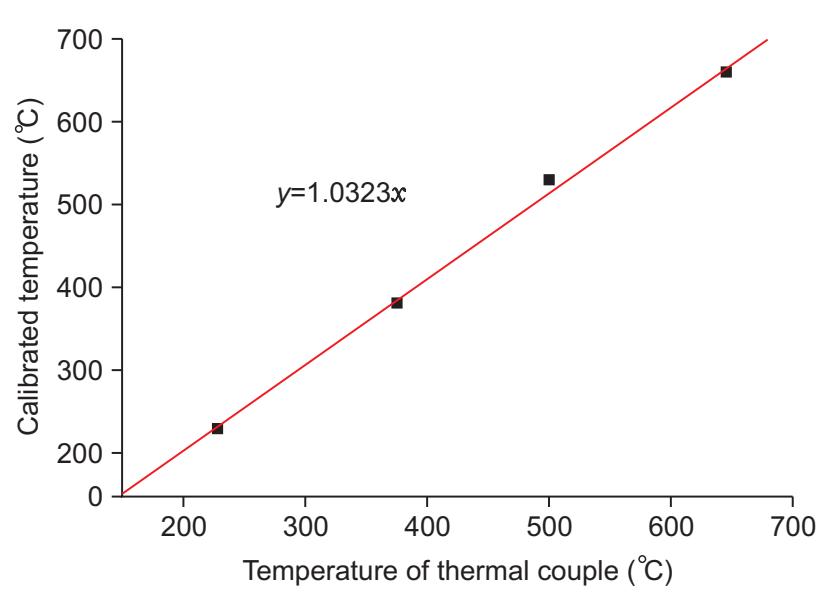

Fig. 5. The calibration curve and fitting formula of the thermocouple readout vs. calibrated temperature.

thermocouple readout, the intensity of the (111) and (220) planes of $\mathrm{NiO}$ decreased while the (200) plane of $\mathrm{Ni}$ appeared in the selected area diffraction patterns (Fig. 3B). This result indicates that the temperature of the TEM specimen and the heating controller differ by $\sim 30^{\circ} \mathrm{C}$ in the intermediate temperature range.

Pure $\mathrm{Al}\left(T_{m}=660^{\circ} \mathrm{C}\right)$ is suitable for measurements performed in the high-temperature range. Like pure $\mathrm{Sn}$, pure $\mathrm{Al}$ was heated to its melting temperature and the solid phase of the specimen was transformed to liquid (Fig. 4) at a measured temperature of $645^{\circ} \mathrm{C}$. Therefore, the actual temperature of the specimen is $15^{\circ} \mathrm{C}$ lower than the indicated temperature of the heating controller.

We produced a thermocouple temperature versus calibrated temperature curve from the experimental data (Fig. 5); this curve was described by a first-degree polynomial (i.e., linear equation) of the form $y=a x+b$. Based on the calibration curve and formula, the actual temperature was related to the thermocouple readout as follows: actual temperature $=1.0323 \times$ thermocouple readout. Therefore, the thermocouple readout temperature can be used to estimate the actual temperature of the specimen. However, this relation is not universal, and therefore each holder should be carefully calibrated.

\section{SUMMARY}

In-situ annealing in TEM allows direct observation of dynamic processes occurring in materials on nanoscale. The method allows individual events to be thoroughly analyzed, enabling direct and precise measurements. The in-situ heating TEM experiment allows us to unambiguously observe the time- and temperature-dependent dynamic reactions of the same specimen. The temperature is a major experimental parameter and must be measured accurately during insitu heating experiments. Therefore, the thermocouple readout of the heating holder must be calibrated prior to the in-situ heating experiment. This calibration can be performed with reference materials that have well-established phase transformation (melting, oxidation, reduction, etc.) temperatures.

In this study, the calibration experiment was performed with four specimens namely, pure Sn, Al-95 wt $\% \mathrm{Zn}$ eutectic alloy, $\mathrm{NiO} / \mathrm{CNT}$ composite, and pure $\mathrm{Al}$ (listed in the order of which the temperature, calibration curve, and formula were obtained). The thermocouple readout of the holder used in this study provided a reliable temperature value with a relative error of $<4 \%$.

\section{CONFLICT OF INTEREST}

No potential conflict of interest relevant to this article was reported.

\section{ACKNOWLEDGEMENTS}

The authors are also grateful for the technical support provided by the cooperative center for research facilities (CCRF) at Sungkyunkwan University. 


\section{REFERENCES}

Beam III E and Chung D D L (1985) Phase transitions in gold contacts to GaAs. Thin Solid Films 128, 321

Bovin J O, Smith D J, and Wallenberg R (1985) Imaging of atomic clouds outside the surfaces of gold crystals by electron microscopy. Nature 317, 47.

Butler E P and Hale K F (1981) Dynamic experiments in the electron microscope. Practical Methods in Electron Microscopy 9, 470.

Cowley J M and lijima S (1972) Electron microscope image contrast for thin crystal Z. Naturforsch. Teil. A 27, 445.

Eyring L, Dutner C, Goral J P, and Holladay A (1985) High-resolution electron microscopic studies of chemical reactions in thin films. Ultramicroscopy 18, 253.

Gibson J M, McDonald M C, and Unterwald F C (1985) Direct imaging of a novel silicon surface reconstruction. Phys. Rev. Lett. 55, 1765.

Glicksman M E and Schaefer R J (1966) In situ measurements of dendrite profiles in pure tin. Acta Metall. 14, 1126.

Glicksman M E and Vold C L (1966) Observation of solidification and melting phenomena in metals using the electron microscope. Acta Metall. 15, 1412.

Hashimoto H, Takai Y, Yokota Y, Endo H, and Fukuta E (1980) Direct observations of the arrangement of atoms around stacking faults and twins in gold crystals and the movement of atoms accompanying their formation and disappearance. Jpn. J. Appl. Phys. 19, L1.

Holloway K and Sinclair R (1987) Amorphous Ti-Si alloy formed by interdiffusion of amorphous Si and crystalline Ti multilayers. J. Appl. Phys. 61, 1359.

lijima S and Ichihashi T (1986) Structural instability of ultrafine particles of metals. Phys. Rev. Lett. 56, 616.

Kang H B (2009) Characterization of interfacial reaction in environmental friendly-solder/Ni-P UBM system. Ph.D dissertation, (Sungkyunkwan University, Seoul).

Lee J G (2006) In situ HREM observation of crystalline-to-gas transition in nanometer-sized Ag particles. Ph.D dissertation, (Osaka University, Osaka).

Menter J W (1956) The direct study by electron microscopy of crystal lattices and their imperfections. Proc. R. Soc. London Ser. A 236, 119.

Olson G L and Roth J A (1988) Kinetics of solid phase crystallization in amorphous silicon. Mater. Sci. Reports 3, 1.

Raaijmakers I J M M, Reader A H, and Van Houtum H J W (1987) Nucleation and growth of titanium silicide studied by in situ annealing in a transmission electron microscope. J. Appl. Phys. 61, 2527.

Sinclair R (1990) Study of interfacial reactions in metal-silicon and related systems by high-resolution electron microscopy and thermodynamic analysis. Mater. Trans. Jpn. Inst. Met. 31, 628.

Sinclair R, Holloway K, Kim K B, Ko D H, Bhansali A S, Schwartzmann A F, and Ogawa $S$ (1989) Microscopy of semiconductor materials. Inst. Phys. Conf. Ser. 100, 599.

Sinclair R and Konno T J (1994) In situ HREM: application to metalmediated crystallization. Ultramicroscopy 56, 225.

Sinclair R, Parker M A, and Kim K B (1987) In situ high-resolution electron microscopy reactions in semiconductors. Ultramicroscopy 23, 383.

Sinclair R, Yamashita T, Parker M A, Kim K B, Holloway K, and Schwartzmann A $F$ (1988) The development of in situ high-resolution electron microscopy. Acta Cryst. A 44, 965.

Smith D J, Ruijter de W J, McCartney M R, and Weiss J K (1993) Applications of electron holography to the study of interfaces. Ultramicroscopy $\mathbf{5 2}$, 591.

Stach E A, Hull R, Bean J C, Jones K S, and Nejim A (1998) In situ studies of the interaction of dislocations with point defects during annealing of ion implanted Si/SiGe/Si (001) heterostructures. Microsc. Microanal. 4, 294.

Yamashita T and Sinclair R (1983) Dynamic observation of atomiclevel events in cadmium telluride by high resolution TEM. Materials Research Society Symposia Proceedings 14, 295. 